\title{
ENRIQUE RODRIGUES-MOURA DESCUBRE EN AUSTRIA UN EJEMPLAR DE LA PRIMERA EDICIÓN DEL QUIJOTE (ENTREVISTA)
}

En diciembre del año 2009, en la Sala Claudina de la Universidad de Innsbruck, en los Alpes austriacos, en una ceremonia solemne presidida por el rector Karlheinz Töchterle, se presentó la edición facsimilar de un ejemplar de la primera edición del Quijote descubierto en las bóvedas de la biblioteca de la Universidad. Ese ejemplar, hoy llamado Quijote de Innsbruck, se hallaba expuesto en una hermética vitrina y llamaba la atención que no se tratara de un enorme mamotreto, sino de un libro que puede caber en una mano. Enrique Rodrigues-Moura, académico nacido en Chile, de origen brasileño, nacionalidad española y trayectoria internacional, pronunció una conferencia en alemán acerca del valioso ejemplar y de la flamante edición facsimilar. En realidad, el ejemplar había sido descubierto, o re-descubierto, por el propio Rodrigues-Moura quien ha dedicado al asunto mucho tiempo y copiosas investigaciones. El excepcional valor del ejemplar consiste no sólo en su perfecto estado de conservación, sino en que se trata del tercero que aparece en el mundo de una especie de pre-edición del Quijote que tuvo lugar en Valladolid en diciembre de 1604, pero que, al igual que los restantes ejemplares conocidos de la primera edición, lleva fecha de 1605.

Eduardo Labarca estuvo presente en esa emocionante ceremonia, conversó con Enrique Rodrigues-Moura sobre la importancia de su "hallazgo" $\mathrm{y}$, lo entrevistó, posteriormente, enviándonos el texto que transcribimos a continuación.

\section{E. L. ¿CÓMO DESCUBRIÓ ESTE EJEMPLAR DE LA PRIMERA EDICIÓN DEL QUIJOTE?}

E. R. M. Cuando llegué a Austria, a finales de 1999, era consciente de que las históricas relaciones culturales y políticas entre Austria y España, especialmente las dinásticas, formaban parte de la historia del país y los territorios que otrora estuvieron bajo el dominio de los Habsburgo. Era cuestión de estar atento y, en algún momento, no sería improbable que me topase con libros o manuscritos que fuesen testigos de las relaciones culturales entre las ramas castellana y austríaca de los Habsburgo. Me interesaba tirar de ese hilo.

\section{E. L. ¿DÓNDE COMENZÓ SU LABOR ACADÉMICA EN AUSTRIA?}

E. R. M. Fue en la Universidad de Graz donde comencé a trabajar con el acervo del lingüista Hugo Schuchardt, fallecido en 1927, un importante académico que mantuvo una activa correspondencia políglota con un número ingente de interlocutores a lo largo del globo. Entre los textos que pasaron por la mano de Schuchardt había una separata, un artículo, del profesor Emil Winkler, a la sazón catedrático en Innsbruck, 


\section{Eduardo Labarca}

quien le informaba del descubrimiento de un ejemplar de la primera edición del Quijote en los fondos de la Biblioteca Universitaria de Innsbruck. Este breve artículo de sólo tres páginas, publicado en 1925, me informó de la existencia del ejemplar. Resultaba extraño que esta publicación no hubiese tenido repercusión entre los hispanistas, especialmente entre los cervantistas, que no la citaban. Como he podido saber más tarde, gracias al profesor Víctor Infantes, de la Universidad Complutense de Madrid, la edición del Quijote que firmaron los cervantistas Rudolph Schevill y Adolfo Bonilla y San Martín entre los años 1928 y 1931, sí menciona este artículo, pero de forma incompleta. El profesor Winkler falleció en 1942 y su obra académica perdió importancia, pues tiene un claro sesgo nacionalsocialista. Su ascenso académico durante el Tercer Reich fue asombroso y veloz, hasta alcanzar la cátedra en Berlín.

\section{E. L. ¿CÓMO LLEGÓ AL EJEMPLAR EN INNSBRUCK?}

E. R. M. Mi viaje a Innsbruck tuvo lugar en el 2003, pues obtuve una plaza de docente en el Departamento de Filología Románica de la Universidad de Innsbruck. En una primera ocasión pude comprobar que el ejemplar citado por Winkler seguía allí, impecable, bien guardado. Es más, había sido Winkler — como se puede leer en su breve artículo de 1925- quien había rescatado el libro de la "misera plebs", son sus palabras, y había exigido que fuese custodiado en la sala de reservados. El catálogo de la Biblioteca Manual que pude consultar informaba de la existencia del ejemplar e incluso una nota mencionaba que se trataba de un ejemplar de la primera edición. No obstante, en la biblioteca no había una conciencia clara del valor bibliográfico y filológico del ejemplar.

E. L. ¿CÓMO FUE SU PRIMER CONTACTO VISUAL Y FÍSICO CON ESE QUIJOTE? ¿QUÉ SINTIÓ LA PRIMERA VEZ QUE LO TUVO EN LA MANO?

E. R. M. Cuando solicité el libro ya sabía que me lo traerían. Y así fue. Con el libro en la mano, me regalé tiempo para observarlo, sopesarlo, sentirlo. Una particularidad muy destacable del ejemplar es su estado de conservación: completo. Es decir, todos sus folios son originales, ninguno es un facsímil, como ocurre con otros ejemplares, especialmente con los que han circulado en manos privadas hasta época reciente. $\mathrm{Si}$ un anticuario tiene un ejemplar del Quijote al que le faltan algunas páginas, se procura papel antiguo y pide en una biblioteca que posea un ejemplar del Quijote unas imágenes de las páginas que le faltan y no tiene más que ejecutar la falsificación. Sólo con calma se percibe la trampa. El ejemplar de Innsbruck está completo. Desde que llegó a Innsbruck no ha salido de Innsbruck.

E. L. ¿QUÉ HIZO DESPUÉS?

E. R. M. Antes de comunicar sin lugar a error del re-hallazgo de un ejemplar de la editio princeps del Quijote, era necesario que me informase sobre la historia del ejemplar, sus particularidades. Era indispensable confirmar si se trataba de la primera edición, fechada en 1605, o de la segunda, que es del mismo año, pues como el libro tuvo cierto éxito comercial, el librero Francisco de Robles sacó, todavía en 1605, una segunda edición, la cual presenta variantes. El ejemplar de Innsbruck forma parte de la primera edición y en la portada consta la fecha de 1605, no obstante, lo singular es 


\section{Enrique Rodrigues-Moura descubre en Austria}

que fue impreso en 1604. Tenía, pues, que informarme bien de este y otros detalles. Y así lo hice, y acabé presentando una comunicación científica en unas jornadas académicas que tuvieron lugar en la Universidad de Graz, en mayo de 2005. Más importante, sin embargo, fue la exposición que realicé, conjuntamente con el bibliotecario Peter Zerlauth, en el Castillo de Ambras de Innsbruck, durante todo el mes de agosto de 2005. Además, con ocasión de esta exposición, la Biblioteca de la Universidad de Innsbruck imprimió un folleto-catálogo de mi autoría que informaba del hallazgo y ofrecía los detalles más importantes de este ejemplar. Envié ese folleto a algunos hispanistas con obra publicada sobre la historia editorial del Quijote. En un libro que publicó en 2005, El texto del Quijote, el profesor Francisco Rico tuvo la delicadeza de citar ese "atinado folleto" y señalar mi "reexhumación" —-son sus palabras- de este ejemplar. A partir de ese momento, el ejemplar de Innsbruck pasó a ser insoslayable para cualquier romanista, hispanista o cervantista. Constaba ya en la bibliografía de obligada lectura. Más recientemente, he participado en el VII Congreso Internacional de Cervantistas que se celebró en octubre de 2009 en Münster, Alemania. Mi texto saldrá publicado en las actas de dicho congreso.

E. L. ¿1604 Ó 1605? ¿CóMO Y CUÁNDO SE PUBLICÓ ESTE EJEMPLAR?

E. R. M. Hacia mediados de julio de 1604, Miguel de Cervantes y Saavedra había presentado al Consejo Real de Castilla un manuscrito intitulado El ingenioso hidalgo de la Mancha, para el que solicitaba licencia y privilegio de impresión. El 20 de julio se decidió que el cronista real Antonio de Herrera leyese el texto y ejerciese las preceptivas funciones de censor. Su positivo parecer —-“será de gusto y entretenimiento al pueblo, a lo cual en regla de buen gobierno se debe tener atención"- va fechado a 11 de septiembre de 1604, en Valladolid, sede por aquellos años de la Corte, luego, también del Consejo Real de Castilla. Algunos días después, una cédula del 26 de septiembre - estamos siempre en 1604- otorgaba la necesaria licencia de impresión y un privilegio para Castilla por el tiempo de diez años. Sólo con ese documento podía el editor, en este caso Francisco de Robles - "librero del Rey nuestro Señor", como consta en la portada del libro- dar la orden de comenzar la impresión. La imprenta elegida, sita en la calle de Atocha de la villa de Madrid, había sido fundada por Pedro Madrigal en 1586, pero tras su fallecimiento en 1593 había pasado a manos de su viuda, María Rodríguez de Ribalde, quien en 1602 había otorgado amplios poderes de regencia a Juan de la Cuesta, nombre que aparece en la portada de la editio princeps del Quijote.

E. L. CURIOSA HiSTORIA ¿CÓMO SIGUE?

E. R. M. Dos meses después de la licencia de impresión, concretamente el 1 de diciembre de 1604, Francisco Murcia de la Llana firmó el Testimonio de las Erratas, por esa fecha el libro ya tenía que estar impreso, puesto que la función de este documento era certificar que no había divergencias significativas entre el original manuscrito aprobado por el censor Antonio de Herrera $-\mathrm{y}$, aunque perdido éste, se supone que rubricado en todas las páginas, como era costumbre- y la versión impresa que se presentaba para control administrativo: "Este libro no tiene cosa digna que no corresponda con su original”. El tiempo de impresión se había extendido, pues, desde finales de septiembre hasta los últimos días de noviembre de 1604. Para 


\section{Eduardo Labarca}

los parámetros de la época, un tiempo ciertamente corto. De todas formas, para que el libro pudiese salir a la venta era necesario todavía superar un último trámite burocrático, conseguir la Tasa, es decir, el documento oficial emitido por el Consejo Real de Castilla que establecía el precio de venta al público. Ejerciendo sus funciones de editor preocupado por la rápida distribución del libro en el mercado, Francisco de Robles envió un conjunto de ejemplares todavía sin encuadernar a Valladolid, para que el Consejo Real de Castilla contase los pliegos de uno de ellos y tasase el libro. Juan Gallo de Andrada firmó la Tasa en Valladolid a 20 de diciembre de 1604, antes de Navidad, y estableció un precio por ejemplar de "doscientos y noventa maravedís y medio". Acto seguido Francisco de Robles mandó componer esta Tasa en una imprenta local de Valladolid, concretamente la de Luis Sánchez, y la incluyó impresa en esos ejemplares que había llevado consigo, por lo que hacia la Nochebuena de ese año de 1604 algunos ejemplares comenzaron a circular en Valladolid y el libro ya se estaba distribuyendo en la ciudad del Pisuerga, aunque en la portada consta el año de 1605. Los ejemplares de esa primera edición que quedaron en Madrid pasaron a contar, ya en 1605, con una versión de la Tasa impresa por Juan de la Cuesta cuya diferencia salta a la vista. Insisto, pues: algunos ejemplares de esta primera edición, que lleva fecha de 1605, estaban listos y circulando en diciembre de 1604 con la Tasa de Valladolid, entre ellos el ejemplar de Innsbruck.

\section{E. L. ¿CUÁNTOS EJEMPLARES EXISTEN DE ESA TIRADA DE 1604 CON LA TASA IMPRESA EN VALLADOLID?}

E. R. M. De la editio princeps existen unos treinta ejemplares conocidos al día de hoy. De ellos, sólo tres poseen la Tasa de Valladolid: el ejemplar de la Real Academia Española de Madrid, el ejemplar de la Newberry Library de Chicago y el ejemplar de Innsbruck. Es muy probable que la nómina de los ejemplares de la editio princeps del Quijote sufra algunas modificaciones en los próximos años, pues ninguna búsqueda bibliográfica se puede cerrar de forma definitiva. A modo de comparación, se puede observar que de las Comedies, Histories \& Tragedies, de 1623, editio princeps de las obras de William Shakespeare - más conocida como First Folio - se conocen más de doscientos ejemplares, y que de la editio princeps de Os Lusíadas, de 1572, del portugués Luís Vaz de Camões, se han localizado poco más de treinta.

\section{E. L. ¿CUÁNTO VALE ESTE EJEMPLAR?}

E. R. M. El precio puede ser muy alto, pero no está en venta, ni lo estará jamás. Y está bien que así sea. Pertenece a la Biblioteca Universitaria y del Land Tirol, según el nombre actual, que antes era simplemente Biblioteca de la Universidad de Innsbruck, y forma parte del patrimonio cultural de Austria. Según ha escrito Víctor Infantes, en 1989 el Quijote, parte I y parte II, tuvo un precio de salida en Sotheby's de un millón y medio de dólares. Hoy día, indudablemente, el precio sería muy superior.

\section{E. L. ¿QUIÉNES TIENEN DERECHO A VERLO, TOCARLO, HOJEARLO?}

E. R. M. Todos tienen derecho a verlo, respetando las medidas de seguridad y conservación establecidas por la biblioteca. Estas medidas de seguridad son buenas, muy buenas. Lo pregunté en su momento y me lo garantizaron. 


\section{Enrique Rodrigues-Moura descubre en Austria}

\section{E. L. ¿NO HAY PELIGRO DE QUE SE DETERIORE?}

E. R. M. Si un cervantista se desplaza a Innsbruck para ver el original, es obvio que conoce el valor del ejemplar y sabrá estudiarlo y cuidarlo a la vez. Las bibliotecas, especialmente las de fondo antiguo, tienen un aire sacrosanto, por mucho que las quieran modernizar. Consciente o inconscientemente, el lector sabe que ahí se guarda el saber de una civilización y el lector respetará el espacio de la biblioteca, del saber, de los libros. En Innsbruck, en la cámara donde se guardan los libros más valiosos, en las que el público no puede entrar, hay unos carteles muy curiosos que dicen en un alemán burocrático, muy oficial: en caso de fuego, salve primero a las personas.

\section{E. L. ¿QUÉ IMPORTANCIA TIENE ESTE DESCUBRIMIENTO?}

E. R. M. Sobre estos temas hay que relativizar. El planeta no dejará de girar por un descubrimiento así, pero para el mundo del cervantismo e incluso en el ámbito de la bibliofilia, es ciertamente un hecho importante. Diría que cuanto más sepamos sobre la historia del libro durante la época de la denominada imprenta manual, que duró hasta la aparición de la linotipia en el siglo XIX, más sabremos sobre la forma como los manuscritos enviados a imprenta se convertían en libros y mejor podremos conservar el patrimonio cultural e intelectual de una comunidad, una región, un país. Es decir, se trata de un valor patrimonial general: historia del libro, de la lectura, de la relación que establece una sociedad con el saber, su forma de transmitirlo, su relación con la ficción.

\section{E. L. ¿Y QUÉ SIGNIFICACIÓN TIENE LA APARICIÓN, PRECISAMENTE, DE UN EJEMPLAR} DEL QUIJOTE?

E. R. M. La historia de la literatura ha entronizado hace ya siglos al Quijote como centro del canon de la literatura en lengua española e, incluso, de la literatura occidental, más aún, de la mundial. Existe aquella cita famosa del cuento de Borges "Pierre Menard autor del Quijote", en la que se dice que el Quijote ha pasado de ser una obra agradable a "una ocasión de brindis patriótico, de soberbia gramatical, de obscenas ediciones de lujo". La crítica literaria suele asociar la publicación del Quijote con el origen de la novela moderna, un naciente género literario en su siglo.

\section{E. L. ¿LOS LECTORES DE LA ÉPOCA LO PERCIBIERON ASÍ?}

E. R. M. Las prisas por sacar el Quijote al mercado fueron muy superiores a la media de la época, incluso a otras obras cervantinas, lo que permite deducir que Francisco de Robles, el editor — quizás también Cervantes- sabía que una narración en prosa de ficciones verosímiles encontraría una acogida muy favorable. En 1599, Mateo Alemán había publicado el Guzmán de Alfarache y con ello había ayudado a dar forma al género picaresco. Las últimas líneas del Guzmán de Alfarache anunciaban una continuación, una segunda parte, que se demoró hasta 1604, aunque el gran éxito del libro propició que le antecediese una continuación apócrifa que llegó a tener hasta diez ediciones entre 1602 y 1604. Es decir, había un ávido público lector a la espera de ficciones verosímiles en prosa y el Quijote podía colmar sus expectativas. Así se entiende la rapidez con la que se imprimió el libro. En directa relación con esas prisas se explica el considerable número de erratas de la editio princeps. Teniendo, pues, presente la novela picaresca como referente - aunque en verdad la reflexión 


\section{Eduardo Labarca}

cervantina establece una discusión poetológica con todos los géneros de su épocahay que observar que Cervantes busca un pacto de confianza entre el narrador y el lector que se base en una relación de igualdad, a la misma altura, como en una mesa de billar. Por el contrario, la picaresca es un género con un narrador autoritario, en primera persona, que narra, desde un determinado momento de su vida, lo que le ha pasado hasta entonces, y esa voz narradora es la única fuente de información: el lector está en sus manos. O confía o no confía. A Cervantes no le convencía esta relación tan autoritaria. Buscó otros caminos, y los experimentó en el Quijote y en otros textos, por ejemplo, en las Novelas ejemplares, que se publicaron en 1613, entre la primera y la segunda parte del Quijote, que es de 1615. Desde la crítica textual se observa que el Quijote se imprimió de prisa y corriendo y, desde la historia de la literatura, se aprecia que a principios del siglo XVII fueron varias las obras en prosa de ficciones verosímiles que buscaron el favor del público. Por ello, se puede comprender mejor en qué marco teórico calza la reflexión poetológica presente en la propia obra de Cervantes, aunque los tratadistas de la época no veían con buenos ojos este nuevo género, hoy día denominado novela. Al mismo tiempo se puede constatar que los libreros, hoy día diríamos editores, invertían sumas importantes de dinero para sacar estos libros al mercado, pues suponían que obtendrían el favor del público. El gusto literario estaba cambiando. Cuanto más sepamos sobre la historia de la publicación del Quijote, más sabremos sobre ese cambio. Y creo, sinceramente, que no es poca cosa, pues estamos hablando de la novela, el género literario por excelencia hoy día.

\section{E. L. ¿CÓMO LLEGÓ ESTE EJEMPLAR A INNSBRUCK?}

E. R. M. La Biblioteca de la Universidad de Innsbruck fue fundada el 22 de mayo de 1745 con el nombre de Bibliotheca Publica Teresiana, también llamada Oenipontana en referencia al nombre latino de la ciudad. En el fondo inicial, compuesto de 12.262 libros, ya se encontraba este ejemplar del Quijote. Hay un vacío documental sobre el viaje que emprendió este ejemplar desde Valladolid, en diciembre de 1604, a Innsbruck, en mayo de 1745. No es improbable que el ejemplar haya llegado a la Corte de Innsbruck al amparo de las relaciones diplomáticas, culturales y, sobre todo, dinásticas que mantuvieron durante todo el siglo XVII las dos ramas de la Casa de los Habsburgo, la castellana y la austriaca. Entre los dos ámbitos eran frecuentes los contactos y desplazamientos de nobles, cortesanos, tropas, sacerdotes, mercaderes con escalas en la ciudad imperial de Innsbruck. Cabe imaginar que algún noble, criado o soldado se haya llevado el libro consigo y por allí se fue quedando.

\section{E. L. ¿POR QUÉ ES EL QUIJOTE TAN IMPORTANTE?}

E. R. M. Por un lado, porque se lee con gran placer, es una novela magnífica, pero eso no deja de ser una opinión personal. Otros preferirán otras obras literarias. Por otro, y ahí no hay subjetividad individual, las sociedades occidentales vivieron el proyecto nacionalista del siglo XIX, en parte todavía vigente, y en ese proyecto nacionalista se buscaba una unidad nacional. Una columna fundamental de ese proyecto era la literatura o la cultura, que se nacionalizó. Y en España se optó por considerar al Quijote como parte de las esencias patrias. Y por eso se entiende bien la cita de Borges: de ser una obra agradable, "una ocasión de brindis patriótico, de soberbia 


\section{Enrique Rodrigues-Moura descubre en Austria}

gramatical, de obscenas ediciones de lujo". Es decir, si el Estado ha decidido que tal libro forme parte central del canon, no se puede hacer nada, ni para bien, ni para mal; o se puede hacer muy poco, el Estado es muy fuerte. El Quijote ha tenido, además, la suerte de formar parte del conjunto de obras que las otras literaturas nacionales también consideran canónicas. Es un grupo reducido de obras, pero son las obras del patrimonio occidental. Don Quijote está loco, pero persigue un ideal, luego no puede estar tan loco como parece, se dijeron los románticos y —estemos o no de acuerdo con esta simplificación - desde esa perspectiva interpretativa, pues tenían razón los románticos. Quien porta el ideal no puede estar loco. Estas simplificaciones interpretativas están ahí, con ellas vivimos, con, contra, por ellas nos batimos. Y es bonito que así sea.

\section{E. L. ¿USTED FORMA PARTE DE LA COMUNIDAD CERVANTINA?}

E. R. M. Si entendemos a la comunidad cervantina como personas que en algún momento de su vida han publicado algún texto de interpretación o divulgación sobre la obra de Cervantes, pues sí, formo parte de esa comunidad. De todas formas, no sólo publico sobre Cervantes ni sólo imparto docencia sobre Cervantes, algo que sería imposible en el sistema germánico, en el que me muevo, donde el docente no puede repetir cursos, tiene que proponer siempre cursos nuevos. Tengo otras líneas de investigación.

E. L. ¿QUIÉNES FORMAN LA COMUNIDAD CERVANTINA? ¿QUÉ TIPO DE GENTE?

E. R. M. No sabría decir cuántas personas se podrían incluir en la comunidad cervantina. Supongo que muchas. El texto del Quijote está ahí y todos pueden opinar. $\mathrm{Y}$ hay opiniones muy variopintas, verdaderamente lunáticas, como si esos investigadores especiales, menos académicos, hubiesen bajado todos a la cueva de Montesinos. Ahora bien, dentro del ámbito académico más profesional, existe un núcleo muy serio de investigadores en torno a la Asociación Internacional de Cervantistas, que organiza congresos cada tres años. Soy miembro de esa asociación desde 2009, no más que un socio que recién se acaba de incorporar a un club internacional de investigadores que ya saben mucho, y de quienes espero aprender y con ellos intercambiar opiniones. Estos investigadores se distribuyen por universidades de todo el mundo, de forma especial España, Europa en general, América del Norte, América Latina, el mundo occidental, con alguna aportación de colegas venidos de otros espacios culturales. Es un foro muy dinámico. El actual presidente se llama José Montero Reguera y es profesor en la Universidad de Vigo, España. Con algunos de estos investigadores tengo más contacto. Uno tiene interlocutores informados al otro lado del correo electrónico. Es una de las partes más bonitas de esta profesión: investigar, publicar y saber que existen interlocutores.

E. L. LA BIBLIOTECA DE LA UNIVERSIDAD DE INNSBRUCK ACABA DE PUBLICAR UNA EDICIÓN FACSIMILAR DEL EJEMPLAR DEL QUIJOTE DEL QUE ESTAMOS HABLANDO. ¿QUÉ FINALIDAD TIENE ESA EDICIÓN?

E. R. M. La fundamental, divulgar la existencia de este ejemplar. Darlo a conocer. Situar la biblioteca de la Universidad de Innsbruck en el mapa cervantino mundial. Además, el valor sentimental que, hablando de libros, no es poco. Se ha procurado, en 


\section{Eduardo Labarca}

común acuerdo con la editorial y con el máximo apoyo de la Universidad de Innsbruck, y gracias, también, a la colaboración de la Universidad de Valladolid, Junta de Castilla y León y la sede central del Instituto Cervantes, que el precio por cada ejemplar no sea prohibitivo. Y se ha conseguido. El precio de venta al público es de $€ 34,90$, gastos de envío aparte. Es decir, incluso un estudiante europeo lo puede comprar sin tener que dejar de comer. Tenga en cuenta que hablamos, además, de un libro con tapas duras, buen papel, con sobrecubierta, de 696 páginas, con un epílogo en castellano y su correspondiente traducción al alemán. Un libro que pesa más de un kilogramo.

\section{E. L. USTED ES EL AUTOR DEL EPÍLOGO ¿CUÁL FUE SU INTENCIÓN?}

E. R. M. Se ha intentado que todo sea comprensible para el lector culto, si bien no especialmente informado en temas de historia del libro en la época de la imprenta manual, y al mismo tiempo que el cervantista, vale decir, el lector informado, no considere que todo lo que se le cuenta sea superfluo. Los lectores dirán si se ha conseguido. Con ese fin el epílogo se ha dividido en cuatro partes: Del manuscrito a la editio princeps del Quijote (1605, pero 1604); Historia del ejemplar de Innsbruck; Glosas y marcas de lecturas del ejemplar de Innsbruck; El valor del ejemplar de Innsbruck. Dejo constancia que en la redacción de este epílogo me he beneficiado del generoso conocimiento de los profesores Víctor Infantes, Emilio Martínez Mata, Ana Martínez Pereira y Francisco Rico.

E. L. ¿QUÉ POSIBILIDADES HAY DE QUE LA BIBLIOTECA NACIONAL Y LAS BIBLIOTECAS UNIVERSITARIAS DE CHILE TENGAN LA EDICIÓN FACSIMILAR?

E. R. M. Las que ellos decidan. El libro tiene un precio muy asequible. El porte puede costar algo, pues el libro tiene presencia y peso. El departamento comercial de la editorial de la Universidad de Innsbruck se encarga de esos temas. Ahí ya no me meto, ni quiero, ni puedo.

\section{E. L. ¿TIENE NUEVOS PROYECTOS CERVANTINOS?}

E. R. M. Quiero seguir con unas ideas cervantinas que tengo, pero más en la línea de interpretación y menos en la de búsqueda de ejemplares, aunque tengo que tirar de los hilos que se han puesto en mi camino, pues podría ser que apareciese uno que otro ejemplar importante del Quijote. Veremos.

Kolschizkygasse 30/12*

A - 1040 Viena (Austria)

eduardo_labarca@yahoo.com 